\title{
Ecological Principles Underpinning Invasive Plant Management Tools and Strategies
}

\author{
By Jeremy J. James, Roger L. Sheley, and Brenda S. Smith
}

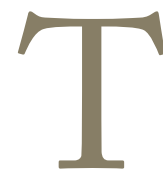

he broad focus of ecologically based invasive plant management (EBIPM) is to identify and repair the major ecological processes facilitating plant invasion. To be useful, however, EBIPM requires that our application of management tools and strategies be based on ecological principles that determine the rate and direction of plant community change. ${ }^{1}$ As a working definition, we can view ecological principles as factors that influence the relative abundance of desired and invasive plants. For example, one widely identified principle may be that morefrequent and intense fires favor the spread of invasive, annual grasses over native, perennial grasses. The formulation of this principle is based on detailed knowledge of the differences in seed production, growth rate, and life history of these species groups. However, we can also think of certain weeds and native plants where this principle may not hold. What this means is that ecological principles are not fixed rules but, instead, are rules that hold under certain sets of conditions. In the above example of invasive annual grasses and fire cycles, these conditions are set by the physiological, developmental, and morphological differences commonly observed between invasive, annual and native, perennial grasses.

We can see from that example that our ability to generate general principles and use that information to develop effective, invasive plant management programs depends strongly on our understanding of mechanisms and processes that drive plant community change. We also know that welldefined principles on which to base application of invasive plant management tools and strategies have been slow to emerge, mostly because of the exceedingly complex nature of biological invasion. To be useful, EBIPM requires that our understanding of the mechanisms and processes directing plant community change be complete enough to create general principles on which managers can base their decisions. ${ }^{1}$

Our objective in this article is to highlight, using key literature examples, how these ecological principles are an important part of the EBIPM model, and how they are used in the EBIPM framework. Based on this knowledge, we can make informed decisions about when various invasive plant management tools and strategies are likely to yield positive results. We outline this discussion around the successional management model developed by Pickett et al. ${ }^{2}$ and used in current EBIPM programs. ${ }^{3}$ These models includes three general causes of plant community change (site availability, species availability, and species performance) and the ecological processes that influence these three general causes. EBIPM is a systems approach for land managers to develop integrated strategies to repair ecological processes to move plant community change in a favorable direction. The ecological principles we detail below describe how ecological processes and conditions influence the relative abundance of invasive and desired plants.

\section{Key Principles Associated With Site Availability} A sufficient amount of safe sites must be available to incoming seeds for species composition to change. A safe site provides the specific set of conditions for a seed to germinate and a seedling to establish and can include factors such as soil water content, air and soil temperature, light, soil organic matter, soil texture, and density, identity and distribution of neighboring plants. Disturbance is the central ecological process affecting site availability. Some form of disturbance is natural in all systems and is key to maintaining recruitment windows for newly arriving and established plants, but disturbance also provides opportunities for invasive plants to establish. Disturbances differ in type, frequency, intensity, and spatial extent. They often kill or damage existing vegetation, decreasing resource uptake by resident vegetation and opening gaps for new seedlings to establish. Several principles provide insight into how disturbance can be managed to favor establishment of desired plants and to discourage establishment and population growth of undesired plants.

Principle: Lower disturbance frequencies will favor establishment of desired plants compared with higher disturbance frequencies. Invasive plants often have more-rapid growth, produce seeds in a shorter amount of time, and place more energy toward seed production than do native plants. ${ }^{4}$ As a consequence of these life-history differences, frequent disturbance 
will tend to favor invasive plants, whereas less-frequent disturbance regimes will tend to favor desired plants.

Principle: Smaller-scale disturbances spread over time will be less likely to promote growth of weed populations than will simultaneous large-scale disturbances. Plants have fixed amounts of resources to allocate to reproduction. As a result, each plant is faced with a trade-off between producing a small amount of large seeds or a large amount of small seeds. Producing a large amount of small seed is assumed to increase the ability of a plant to colonize a safe site, whereas producing a small amount of large seed is expected to improve the ability of a plant to establish under harsh conditions or where competition from neighbor plants may be high. Most invasive plants share traits of colonizing species, producing many small seeds. This strategy is expected to be favored in areas with large-scale disturbances where population growth is primarily limited by the amount of seed a plant can disperse across the landscape. ${ }^{4}$ Likewise, rapid germination and low seed-dormancy mechanisms can allow invasive plant seedbanks to quickly and uniformly respond to a disturbance but have minimal seed carryover in the seedbank. Because of the general differences in seed production and seedbank dynamics, smaller-scale disturbances will be less likely to favor invasive plants compared with largerscale disturbances.

\section{Key Principles Associated With Species Availability}

Seedbanks for desired plants often are low or absent in degraded and weed-infested systems, and seeding often is required to move these systems toward more desirable plant community states. Seed limitations can be due to both dispersal limitations (i.e., where the seeds end up at a site) and the amount of seeds produced at a site. In general, colonization of a safe site by a plant is viewed as a probabilistic event determined by the amount of seeds produced or sown, the frequency of seed dispersal, the competitive ability of seeded species, and the arrival order in which different plants land on a safe site. ${ }^{5}$ The general principles of how species availability can be managed to positively influence desired plants and negatively influence invasive plants are based on the amount and timing of seed dispersal, as well as the competitive ability of seeded species.

Principle: Increasing frequency and amount of seeds dispersed by desired plants and decreasing frequency and amount of seeds dispersed by undesired plants can allow plant communities to change in a favorable direction. In systems that display some degree of heterogeneity in site availability, successful colonization of a site by a particular plant is probabilistic. Lottery models have been used by researchers to describe some of these dynamics. In these models, seeds of species that successfully colonize sites are drawn randomly from a pool of potential species. Species that produce more seeds or are sown at higher rates and species where seeds are dispersed more frequently have a greater probability of colonizing a safe site. ${ }^{5}$ Managers can facilitate plant community change toward a desired state by increasing the amount and dispersal frequency of desired plants and/or decreasing the amount and dispersal frequency of undesired plants.

Principle: Less-competitive, desired plants can "win" a safe site from more-competitive, invasive plants by arriving at the safe site first. Competitive hierarchies have been widely demonstrated in plant ecology, leading to the question of how lesscompetitive plants can establish in areas where competitive plants are present. Small differences in the order in which seeds arrive at a site (e.g., weeks), can influence which plants establish and, ultimately, the composition of the community. ${ }^{6}$ In general, plants that arrive first tend to be most successful. Because of this "priority effect," when a weak competitor arrives first, it can persist even when more-competitive plants subsequently establish. Consequently, small shifts in dispersal timing that favor early dispersal of desired plants and delay dispersal of undesired plants can facilitate plant community change toward a desired state.

\section{Key Principles Associated With Species Performance}

Species performance is determined by a number of ecological processes that influence how a species captures and uses resources to maintain and increase population size. These processes include resource-supply patterns of the ecosystem (resources); physiological processes that allow a plant to affect and respond to the immediate environment (ecophysiology); the patterns of birth, mortality, and growth of individuals in a population (life history); how a plant responds and maintains fitness under harsh, abiotic conditions (stress); and how a plant is influenced by neighbors of different species (interference). Not all processes necessarily need to be managed in every situation, and by understanding the key principles associated with how these processes influence plant performance, it may be possible to identify the most-effective management strategy and tools.

Principle: Managing environments for low resource availability will favor resource conservation over resource capture by plants, favoring desired plants over invasive plants. Research on how plants construct their leaf and root tissue indicates that native plants often produce tough, long-lived tissue capable of yielding a long return on the biomass invested, whereas invasive plants tend to construct thin, short-lived tissue, capable of yielding short returns on the biomass invested. ${ }^{7}$ Investing biomass in thin, short-lived root and leaf tissue allows invasive plants to grow much faster in resource-rich environments compared with desired plants. Managing environments for low resource availability, therefore, should favor performance of desired plants over invasive plants.

Principle: Initial establishment of desired plants needs to be successfully managed to realize any benefit of resource management on desired-plant establishment. The resource conservation traits generally displayed by native plants (e.g., thick root and leaf tissue) provide an advantage to desired species in resource-poor environments, but it often takes substantial time for the benefits of these traits to accrue. When desired plants establish from seeds, these resource-conservation traits 
do not provide native plants with a competitive advantage over invasive plants during the first growing season. Over multiple years, however, these resource-conservation traits allow native plants to build up larger internal pools of resources, such as nitrogen, and ultimately, to provide native plants a competitive advantage over invasive plants in lowresource environments. ${ }^{8}$ For seeded, desired species to take advantage of low-resource environments, seed production and rapid growth of invasive plants will need to be carefully managed during the first growing season.

Principle: Within a given community, managers can minimize resource availability primarily by maximizing biomass and then by managing for variation in traits such as phenology and root distribution of dominant species. Researchers have spent time examining how plant diversity influences resource availability and invasion resistance, but, in many cases, it is the absolute biomass of the dominant plants in the plant community that sequesters the most resources and yields the greatest amount of invasion resistance. ${ }^{9}$ When considering the primary importance of abundance, plant communities that have codominant plants that differ in phenology and root distribution or other traits that influence the pattern of resource capture can sequester more resources than monocultural communities. This suggests managers can minimizes resource availability by first managing for biomass and then, subsequently, managing for variation in traits among potentially dominant plants.

Principle: Managers can minimize the amount of resources directly available to an invader by establishing desired plants that are functionally similar to an invader. Plants within a functional group (e.g., shrubs, grasses, forbs) that share similar phenology, root distribution, and life history tend to have similar patterns of resource acquisition. The functional identity of the invasive plants can be a major factor in determining which groups of native plants will yield the greatest degree of invasion resistance. ${ }^{10}$ Desired plants that are functionally similar to invasive plants will have a disproportionately greater negative effect on resources available to the invasive plant than would be predicted by their biomass alone.

\section{Management Implications}

As our research and understanding of invasive plant management and restoration develops, we have the difficult task of trying to consolidate this information into salient principles that can help guide decision making and to predict how specific management is likely to influence plant community dynamics. In this article, we have outlined a handful of ecological principles that we argue can be formulated based on our current understanding of ecology and invasive plant management. Critical to this formulation and our ability to make these principles useful is understanding the ecological conditions and processes that determine when these principles are likely to hold and the situations in which these principles are unlikely to hold. This initial effort recognizes that identification of ecological principles and the conditions in which they hold are still being developed, and it is expected that these general principles will be expanded, modified, and improved. Nevertheless, this initial effort shows the critical need for basic and applied ecology to work jointly on development of general principles that will allow restoration and other land management activities to move away from purely agronomic-based approaches and toward approaches that explicitly incorporate ecological principles into the decision-making processes. Ultimately, this will be helpful in moving restoration and weed management from a site by site basis toward approaches that can be applied across a range of restoration scenarios.

\section{References}

1. Werner, P. 1999. Reflections on "mechanistic" experiments in ecological restoration. In: W. R. Jordan III, M.E. Gilpin, and J. D. Aber [EDs.]. Restoration ecology: a synthetic approach to ecological research. 4th ed. Cambridge, UK: Cambridge University Press. p. 321-328.

2. Pickett, S. T. A., S. L. Collins, and J. J. Armesto. 1987. A hierarchical consideration of causes and mechanisms of succession. Vegetatio 69:109-114.

3. Sheley, R., J. James, B. Smith, And E. Vasquez. 2010. Applying ecologically based invasive-plant management. Rangeland Ecology \& Management 63:605-613.

4. Noble, I. R., and R. O. Slatyer. 1980. The use of vital attributes to predict successional changes in plant communities subject to recurrent disturbances. Vegetatio 43:5-21.

5. SAlE, P. F. 1977. Maintenance of high diversity in coral reef fish communities. The American Naturalist 111:337-359.

6. Egler, F. E. 1952. Vegetation science concepts, I: initial floristic composition, a factor in old-field vegetation development. Vegetatio 4:412-417.

7. Wright, I. J., P. B. Reich, M. Westoby, D. D. Ackerly, Z. Baruch, F. Bongers, J. Cavender-Bares, T. Chapin, J. H. C. Cornelissen, M. Diemer, J. Flexas, E. Garnier, P. K. Groom, J. Gulias, K. Нikosaka, B. B. Lamont, T. Lee, W. Lee, C. Lusk, And J. J. Midgley. 2004. The worldwide leaf economics spectrum. Nature 428:821-827.

8. Berendse, F., W. T. Elberse, and R. Geerts. 1992. Competition and nitrogen loss from plants in grassland ecosystems. Ecology 73:46-53.

9. Grime, J. P. 1998. Benefits of plant diversity to ecosystems: immediate, filter and founder effects. Journal of Ecology 86:902-910.

10. Symstad, A. J. 2000. A test of the effects of functional group richness and composition on grassland invasibility. Ecology 81:99-109.

Authors are Director, Sierra Foothill Research and Extension Center, Dept of Agriculture and Natural Resources, University of California, Browns Valley, CA 95918,USA, jjjames@ucanr.edu (James); Ecologist, USDA-ARS Eastern Oregon Agricultural Research Center, Burns, OR 97720, USA (Sheley); and Outreach and Education Coordinator, USDA-ARS Eastern Oregon Agricultural Research Center, Burns, OR 97720, USA (Smith). 